\title{
Large carbon sink potential of Amazonian Secondary Forests to mitigate climate change
}

\author{
Viola Heinrich ( $\nabla$ viola.heinrich@bristol.ac.uk) \\ University of Bristol https://orcid.org/0000-0003-0501-0032
}

\section{Ricardo Dalagnol}

National Institute for Space Research (INPE)

\section{Henrique Cassol}

National Institute for Space Research https://orcid.org/0000-0001-6728-4712

\section{Thais Rosan}

College of Life and Environmental, University of Exeter

\section{Catherine Torres de Almeida}

National Institute for Space Research (INPE)

\section{Celso H. L. Silva Junior}

Instituto Nacional de Pesquisas Espaciais - INPE https://orcid.org/0000-0002-1052-5551

\section{Wesley Campanharo}

National Institute for Space Research (INPE) https://orcid.org/0000-0001-5719-8407

\section{Joanna House}

Cabot Institute, University of Bristol https://orcid.org/0000-0003-4576-3960

\section{Stephen Sitch}

University of Exeter https://orcid.org/0000-0003-1821-8561

\section{Tristram Hales}

Cardiff University

\section{Marcos Adami}

Instituto Nacional de Pesquisas Espaciais (INPE) https://orcid.org/0000-0003-4247-4477

\section{Liana Anderson}

INPE https://orcid.org/0000-0001-9545-5136

\section{Luiz Aragão}

National Institute for Space Research

\section{Article}

Keywords: Carbon Sequestration, Environmental Variability, Anthropogenic Disturbances, Spatial Patterns, 
DOI: https://doi.org/10.21203/rs.3.rs-71626/v1

License: (c) (1) This work is licensed under a Creative Commons Attribution 4.0 International License. Read Full License

Version of Record: A version of this preprint was published at Nature Communications on March 19th, 2021. See the published version at https://doi.org/10.1038/s41467-021-22050-1. 
1 Large carbon sink potential of Amazonian Secondary

2 Forests to mitigate climate change

3 Authors

4 Viola H. A. Heinrich ${ }^{1 *}$, Ricardo Dalagnol ${ }^{2}$, Henrique L. G. Cassol ${ }^{2}$, Thais M. Rosan ${ }^{3}$, Catherine Torres

5 de Almeida ${ }^{2}$, Celso H. L. Silva Junior ${ }^{2}$, Wesley A. Campanharo ${ }^{2}$, Joanna I. House ${ }^{1,4}$, Stephen Sitch $^{3}$,

6 Tristram C. Hales ${ }^{5}$, Marcos Adami $^{6}$, Liana O. Anderson ${ }^{7}$, Luiz E. O. C. Aragão ${ }^{2,3 *}$

$7 \quad$ Affiliations and Addresses

$8 \quad{ }^{1}$ School of Geographical Sciences, University of Bristol, Bristol UK.

$9 \quad{ }^{2}$ Remote Sensing Division, National Institute for Space Research (INPE), São José dos Campos, Brazil.

$10{ }^{3}$ College of Life and Environmental Sciences, University of Exeter, Exeter, UK.

$11{ }^{4}$ Cabot institute, University of Bristol, Bristol, UK.

${ }^{5}$ School of Earth and Ocean Sciences, Cardiff University, Cardiff, UK.

${ }^{6}$ Amazon Regional Center, National Institute for Space Research (INPE), Belém, Brazil.

${ }^{7}$ National Center for Monitoring and Early Warning of Natural Disaster, São José dos Campos, Brazil.

Corresponding author Contact:

*Email: viola.heinrich@bristol.ac.uk; luiz.aragao@inpe.br

Abstract

Secondary forests (SF) have a large climate mitigation potential, given their ability to sequester carbon up to 20 times faster than old-growth forests. Environmental variability and anthropogenic disturbances lead to uncertainties in estimating spatial patterns of SF carbon sequestration rates. Here we quantify the influence of environmental and disturbance drivers on the rate and spatial patterns of regrowth in the Brazilian Amazon, by integrating a 33-year land cover timeseries with a 2017 Aboveground Biomass dataset. Carbon sequestration rates of young Amazonian SF ( $<20$ years old) are at least twice as high in the west $\left(3.0 \pm 1.0 \mathrm{MgC} \mathrm{ha}^{-1} \mathrm{yr}^{-1}\right)$ than in the east $\left(1.3 \pm 0.3 \mathrm{MgC} \mathrm{ha}^{-1} \mathrm{yr}^{-1}\right)$. Disturbances reduce $\mathrm{SF}$ regrowth rates by 8-50\% $(0.6-1.3$ $\mathrm{MgC} \mathrm{ha}^{-1} \mathrm{yr}^{-1}$ ). We estimate the $2017 \mathrm{SF}$ carbon stock to be $294 \mathrm{TgC}$, which could be $8 \%$ higher by avoiding fires and repeated deforestation. Maintaining the $2017 \mathrm{SF}$ area has the potential to

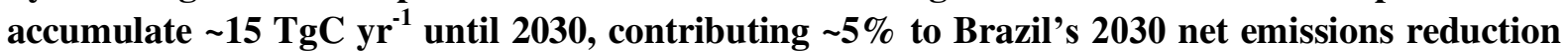
target. Supporting SF and old-growth forests conservation alongside the expansion of SF in deforested areas is therefore a viable nature-based climate mitigation solution.

\section{Introduction}

Global forests are expected to contribute a quarter of the pledged mitigation under the 2015 Paris Agreement, by limiting deforestation and by encouraging forest regrowth ${ }^{1}$. The Brazilian Amazon biome (Amazonia) is the largest continuous tropical forest on Earth, occupying 3\% of terrestrial land. It stores approximately $10 \%$ of the global forest carbon $(120 \mathrm{Pg} \mathrm{C})^{2,3}$ and between 2000 and 2010

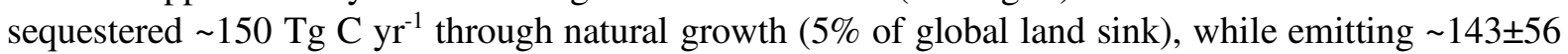
$\mathrm{Tg} \mathrm{C} \mathrm{^{-1 }}$ through deforestation ( 1.4\% of global carbon emissions $)^{4-6}$. As part of their Nationally Determined Contributions (NDC) to the Paris Agreement, Brazil has pledged to restore and reforest 12 million hectares of forests by 2030 to contribute to net emission reductions ${ }^{7}$. Part of this reduction can 
be achieved by the natural regeneration of secondary forest (SF) on abandoned land, which are already regrowing on $\sim 20 \%$ of deforested land in Amazonia $^{8-10}$.

Previous estimates of average net carbon uptake in young ( $<20$ years old) SF range between $2.95 \pm 0.4$ and 3.05 $\pm 0.5 \mathrm{Mg} \mathrm{C} \mathrm{ha}^{-1} \mathrm{yr}^{-1}, 11-20$ times larger than old-growth primary forests ${ }^{11,12}$. These estimates, which are based on limited field data across the Neotropics, are unable to capture the different spatial patterns and rates of SF carbon sequestration which are influenced by several drivers. This includes environmental drivers such as shortwave radiation, precipitation, soil fertility and forest water deficit, as well as anthropogenic disturbances like fire and deforestation cycles ${ }^{11,13-16}$. The SF carbon stock of regions with very high-water deficit $\left(-1,200 \mathrm{~mm} \mathrm{yr}^{-1}\right)$ can be up to $85 \%$ lower compared to no water deficit $\left(0 \mathrm{~mm} \mathrm{yr}^{-1}\right)$ regions in the Neotropics ${ }^{11}$. The effects of these drivers are not limited to SF growth, nor are they static over space and time, affecting the magnitude of forest carbon sequestration and stocks ${ }^{17}$. A recent study showed that rising annual mean temperatures and drought reduced tree growth in Amazonian old-growth forests ${ }^{4}$. This effect, coupled with ongoing deforestation suggests that the sink in these forests peaked in the 1990s and is now steadily declining ${ }^{4}$. Considering these changes, it is important to also obtain a wider spatial and temporal understanding of drivers affecting the magnitude and sustainability of SF regrowth.

Remote sensing products can be used to study these effects, offering broad spatial and temporal coverage. With the availability of nearly four decades of Landsat data (30 m spatial resolution), it is now possible to track the fate of deforested areas over time, which includes the changing demography of SF across Amazonia ${ }^{10,18}$. According to satellite-based analysis, SF are typically part of a 5-10 year cycle of clearance and abandonment since they are currently not protected by national policies aimed at curbing deforestation ${ }^{19,20}$. These repeated deforestations are expected to decrease the carbon sink of future regrowth forests. Deforestation of SF amounted to 70\% of total Amazonian forest loss between 2008 and $2014^{21}$. However, the relationship between SF regrowth and environmental and disturbance drivers has never been explored spatially-explicitly using global remote sensing products.

Here we aim to produce unique estimates of SF regrowth by constructing spatially explicit models based on multi-satellite products to quantify the carbon sequestration potential of Amazonian SF exposed to multiple environmental and anthropogenic disturbance drivers. We use a novel approach to map SF annually from 1985 to 2017 and determine their ages ${ }^{10,18}$, and provide the first applications of these maps to analyse SF regrowth in terms of Aboveground Carbon (AGC) ${ }^{22-24}$. We present a map of Amazonian SF regrowth rates with the quantification of the contemporary SF carbon sink considering the impact of different drivers on AGC accumulation. We use this to model the future carbon sequestration potential of SF relative to the Brazilian NDC targets.

\section{Results}

\section{Impact of drivers on Secondary Forest regrowth}

We used the land cover product MapBiomas (Collection 3.1) to identify secondary forests and their ages from 1985 to 2017 and used the European Space Agency Climate Change Initiative (ESA-CCI) Aboveground Biomass product to construct the regrowth of SF across Amazonia ${ }^{22,24}$. Based on these two products, we identified and tested the effects of six key drivers on SF regrowth and AGC accumulation: (1) Average annual shortwave (SW) radiation ${ }^{25}$; (2) Average annual precipitation ${ }^{26}$; (3) Forest water deficit using the Maximum Cumulative Water Deficit index (MCWD) $)^{27,28}$; (4) Soil fertility using the Soil Cation Concentration (SCC) as a proxy ${ }^{29}$; (5) Burned area ${ }^{30}$; and (6) Repeated deforestations (this study - see Methods; Supplementary Table 1). Our analysis reveals that there are significant differences in AGC accumulation in SF considering these different drivers (Figure 1; Supplementary Figures 1-6; Supplementary Tables $2-7)$. After forest age, SW radiation is the most important variable influencing AGC (Figure $1 \mathrm{~g})$. In areas of very low annual SW radiation $\left(<170 \mathrm{Wm}^{-}\right.$ $\left.{ }^{2}\right)$, the overall regrowth rate is almost three times greater compared to areas of high SW radiation $(>187$ 
$\left.\mathrm{Wm}^{-2}\right), \sim 3.4 \pm 0.6$ and $\sim 1.3 \pm 0.4 \mathrm{Mg} \mathrm{C}^{-1} \mathrm{yr}^{-1}$, respectively. MCWD was the second most important driver, where areas with very low MCWD $\left(>-180 \mathrm{~mm} \mathrm{yr}^{-1}\right)$ assimilate almost double the carbon compared to areas with very high MCWD $\left(<-350 \mathrm{~mm} \mathrm{yr}^{-1}\right)$ in the first 20 years of regrowth $(\sim 2.7 \pm 0.7$ $\mathrm{Mg} \mathrm{Cha} \mathrm{yr}^{-1}$ and $\sim 1.5 \pm 0.2 \mathrm{MgC} \mathrm{ha}^{-1} \mathrm{yr}^{-1}$, respectively). Similar differences in the regrowth rates can be observed under conditions of low mean annual precipitation (<1920 mm $\left.\mathrm{yr}^{-1}\right)$ compared to moderate and high conditions (1920-2210 $\mathrm{mm} \mathrm{yr}^{-1}$ and $>2210 \mathrm{~mm} \mathrm{yr}^{-1}$, respectively). There was no statistical difference in carbon accumulation under different SCC conditions, furthermore the expected trend, increased carbon accumulation with increased soil fertility, is reversed, probably due to the dominant effect of the other environmental drivers ${ }^{31,32}$ (Figure 1d; Supplementary Table 4).

For most of our modelled regrowth curves, SF were able to reach AGC levels equivalent to those of old-growth forests, however the time taken to reach these levels is generally more than a century (Supplementary Table 8). Our results also show that in areas of anthropogenic disturbance such as fires and repeated deforestations, the carbon accumulation was up to 3.8 times slower and even plateaued within 20 to 40 years, thus potentially never recovering to old-growth forest AGC values (Figure 1e and 1f; Supplementary Table 8). Our results showed that fire occurrence and repeated deforestations were the least important drivers for modelling AGC regrowth across the entire biome. This is in part an artefact of the small number of SF plot being exposed to multiple fires (28.2\%) and repeated deforestations (11.3\%) (Supplementary Figure 8).
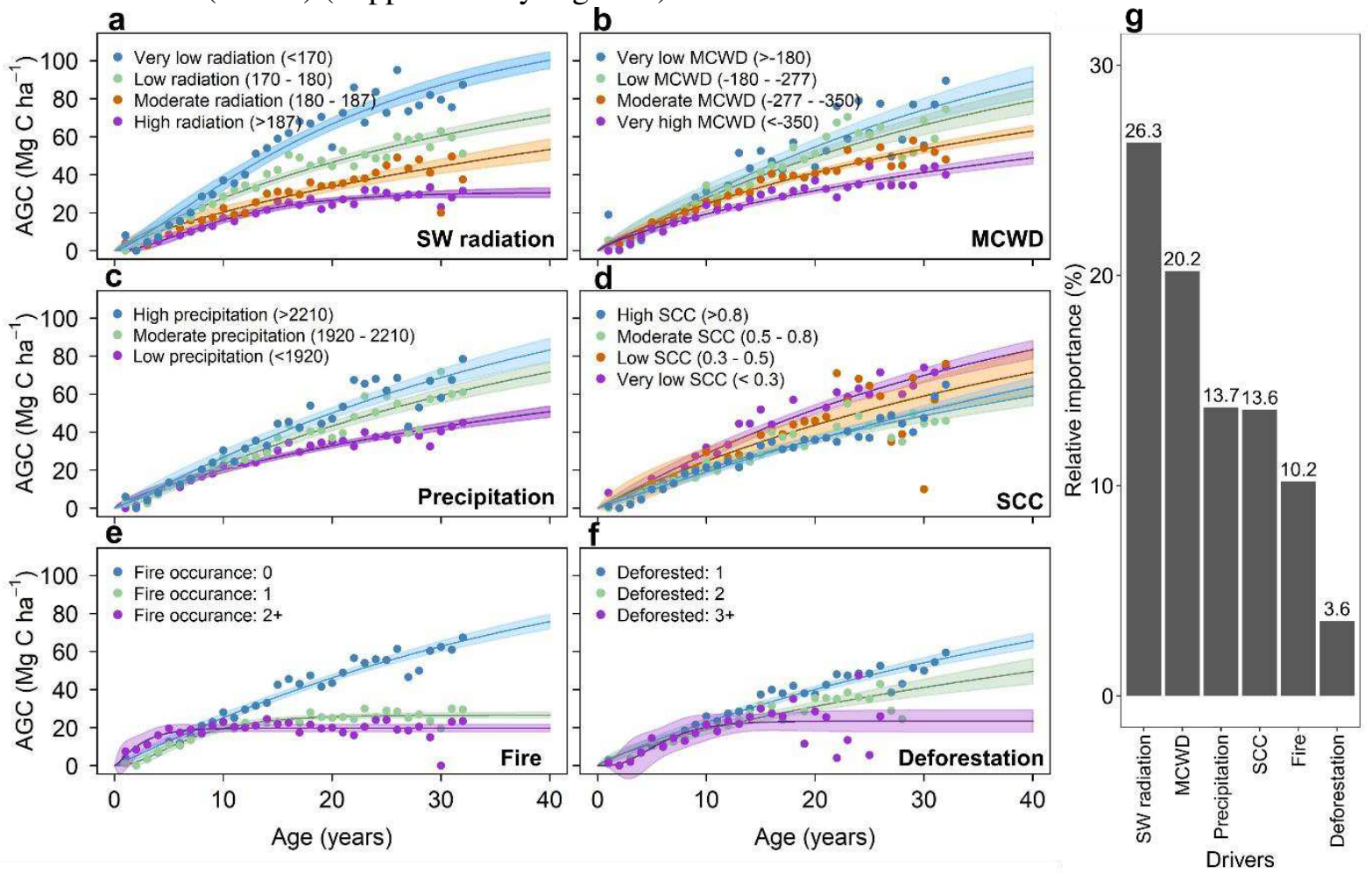

Figure 1 | Secondary forest carbon accumulation with increasing age under different driving conditions. Drivers are (a) Annual mean downward shortwave radiation $\left(W^{-2}\right)$, (b) Maximum Cumulative Water Deficit (MCWD; mm yr $\left.{ }^{-1}\right)$, (c) Annual mean precipitation $\left(\mathrm{mm} \mathrm{yr}^{-1}\right)$, (d) Soil Cation Concentration (SCC; cmol $\left.(+) \mathrm{kg}^{-1}\right)$, (e) Fire occurrences between 2001 and 2017 , (f) Number of repeated deforestations between 1985 and 2017, where 1 refers the initial conversion from old-growth forest to other land. The bar graph (g) shows the importance of the drivers (a-f) in influencing AGC relative to the importance of Forest age (100\% - not shown in figure). Shading in (a-f) denotes the 95\% confidence interval of the models, based on the median value of the initial data for each age - dots in figures.

\section{Mapping the spatial patterns of regrowth}

To analyse the spatial variation of regrowth rates in our models, we identified different regions of Amazonia according to the three most important environmental drivers influencing carbon 
accumulation (Figure 1g), SW radiation, annual precipitation, and MCWD (Figure 2a). These were then used to model the SF regrowth in a spatially explicit manner and according to different types of disturbances; fire and deforestation (Figure 3). Our analysis shows distinct regrowth regimes emerging in these four heterogeneous environmental regions (Figure 3). In the North-West, a region with generally high precipitation (mean of $2049 \mathrm{~mm} \mathrm{yr}^{-1}$ ), low SW radiation (mean of $163.6 \mathrm{Wm}^{-2}$ ) and little to no water deficit (MCWD mean of $-64.4 \mathrm{~mm} \mathrm{yr}^{-1}$; Supplementary Figure 8), regrowth rates were generally the highest and hardly influenced by any kind of disturbance. Here regrowth rates ranged between $2.4 \pm 0.8-3.0 \pm 1.0 \mathrm{Mg} \mathrm{C} \mathrm{ha}^{-1} \mathrm{yr}^{-1}$ in the first 20 years of regrowth (Figure 3a; Supplementary Table 9). In contrast, the eastern and southern parts have slower overall regrowth rates $(1.3 \pm 0.3-$ $1.8 \pm 0.3 \mathrm{Mg} \mathrm{C} \mathrm{ha}^{-1} \mathrm{yr}^{-1}$ in the first 20 years) with fire and deforestation disturbances reducing their regrowth by around $50 \%$ to as low as $0.6 \mathrm{Mg} \mathrm{C} \mathrm{ha}^{-1} \mathrm{yr}^{-1}$ in the first 20 years (Figure $3 \mathrm{~b}-\mathrm{d}$ ). In the North-East and South-Western regions fire disturbance is the third and second most important driver respectively to influence the AGC (Figure 2c and d).

We validated our models with field AGC estimates of SF collected across Amazonia (284 samples across 33 locations) and found that our AGC estimates are statistically similar $(p>0.01)$ within the four regions identified in Figure 2a (Supplementary Figure 10). We also compared the regional models with basin-wide models used in previous studies and within the Brazilian Greenhouse Gas Inventory, which do not consider different environmental or anthropogenic disturbance drivers ${ }^{21,33,34}$. In the western regions, during the first 10 years of growth, our models of 'no disturbance' were visually very similar to the other models (Supplementary Figure 11). We found no significant difference to AGC estimates from the model used in previous research $(p>0.01$; Supplementary Table 11). Estimates using the equation from the Brazilian Greenhouse Gas inventory were significantly higher across the 40 years

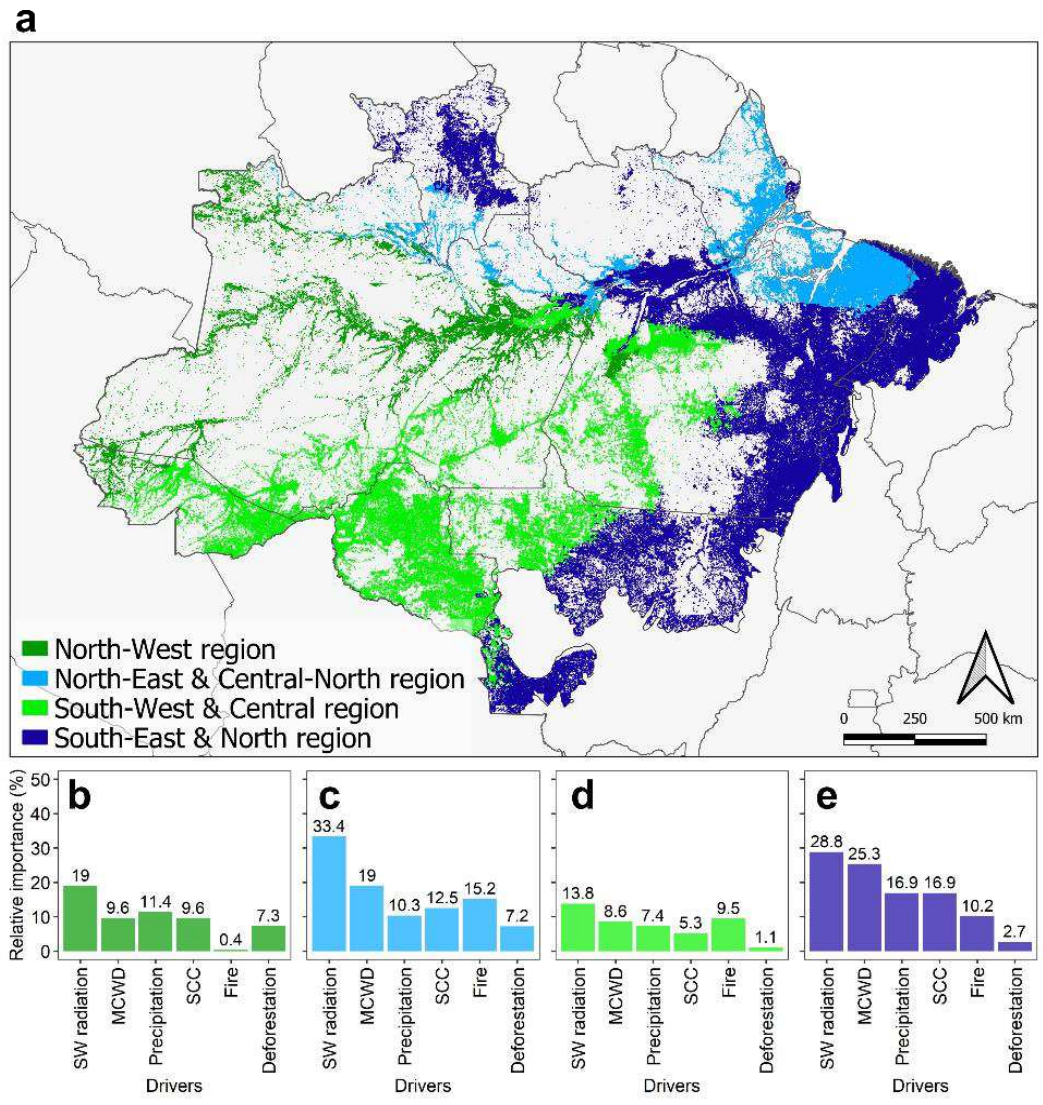

Figure 2 | Secondary Forests grouped by climatological similarities. Regions are grouped according to similarities in Maximum Cumulative Water Deficit (MCWD), annual average downward shortwave radiation and annual average precipitation (a). The importance of different drivers relative to Forest age is shown (most important$100 \%$, not shown) for the North-West region (b), North-East and Central-North region (c), South-West and Central region (d), South-East and North region (e). See Supplementary Table 9 for quantitative interpretations of the regions. 

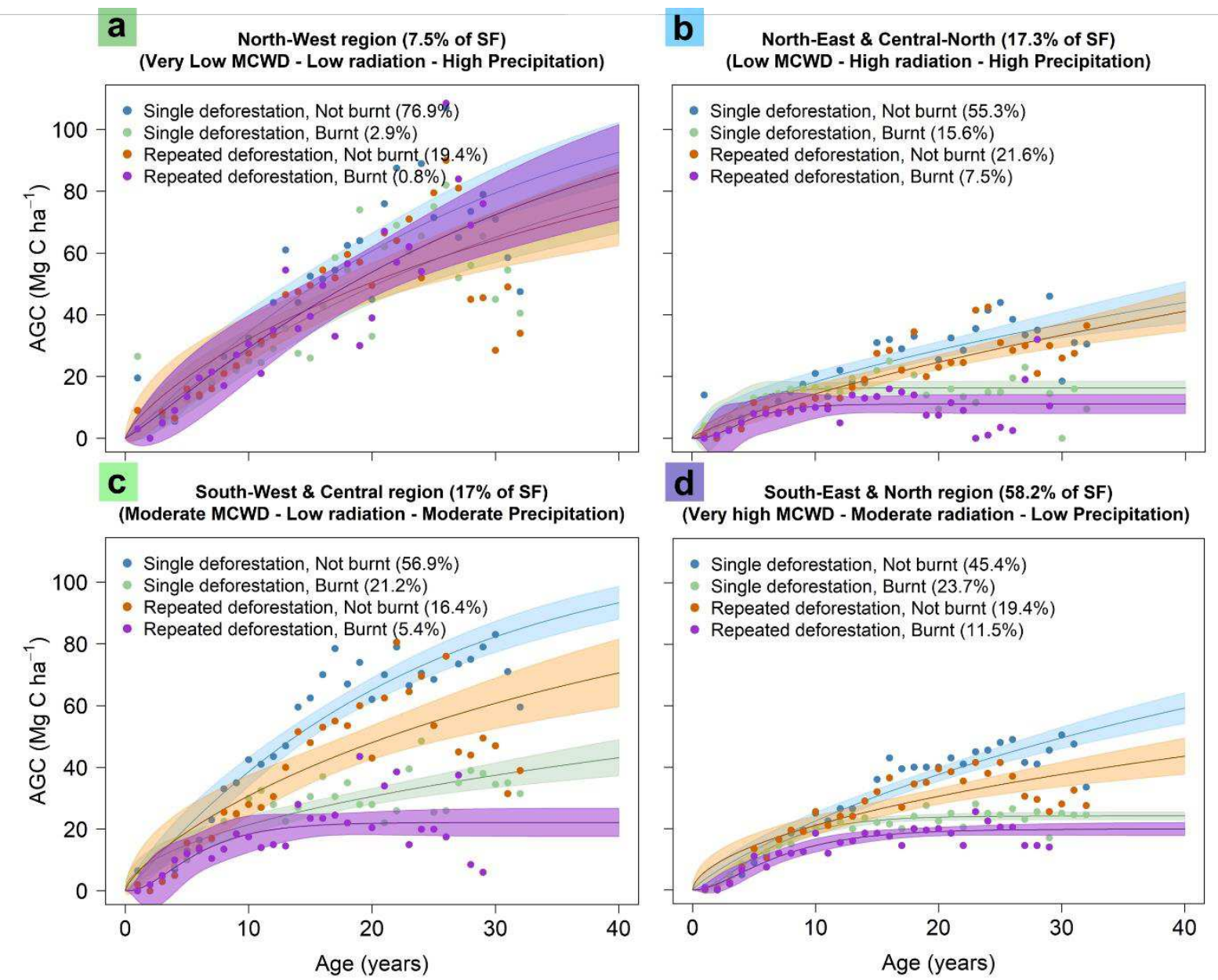

Figure 3 | Region-specific regrowth models of AGC in secondary forests. The corresponding secondary forest (SF) regrowth models for the regions identified in Figure 2a. In each region, the climatological variables (Maximum Cumulative Water Deficit (MCWD), Shortwave radiation and annual precipitation are similar and the regrowth due to different kinds of disturbance is shown. (a) North-West region, (b) North-East and Central-North region, (c) South-West and Central region, (d) South-East and North region. The legends show the number of secondary forests that are affected by the type of disturbance in each region. Shading denotes the $95 \%$ confidence interval of the models based on the median value of the initial data for each age - dots in figures. See Supplementary Table 9 for quantitative interpretations of the qualitative definitions given here, for example "Low precipitation".

\section{Modelling the 2017 and future secondary forest sink}

We quantify the net AGC change for the year 2017 by explicitly considering the changes in SF area from 2016 to 2017, the four environmental regions and the disturbances these forests experienced in the two years to apply the relevant regrowth model seen in Figure 3. Our results show that new regenerating forests and existing SF combined resulted in a carbon sink of $28 \mathrm{Tg} \mathrm{C} \mathrm{yr}^{-1}$, at the expense of 16.1 $\mathrm{Tg} \mathrm{C} \mathrm{yr}^{-1}$ emitted from SF loss, resulting in a net SF carbon sink of $\sim 12 \mathrm{Tg} \mathrm{C} \mathrm{yr}^{-1}$ (Figure 4). We find the total carbon stored in all Amazonian SF in 2017 to be approximately 294Tg C (Figure 4d). We also estimate that the potential carbon stock if all SF had regrown without experiencing any disturbances, namely fire and repeated deforestations, could have reached $320 \mathrm{Tg} \mathrm{C}$ in 2017. 
Finally, to quantify the potential of the existing 2017 SF to contribute to reducing future net carbon emissions according to Brazil's NDC, we model future potential stocks and annual carbon sink for the decade ahead by considering various levels of preservation (Figure 5). In 2025 we project an 82\% difference in carbon accumulation between the most ambitious preservation plan (preserving all 13.8 Mha of SF) and the least ambitious plan (preserving 2.2 Mha including only SF older than 20 years in 2017; Figure 5b).

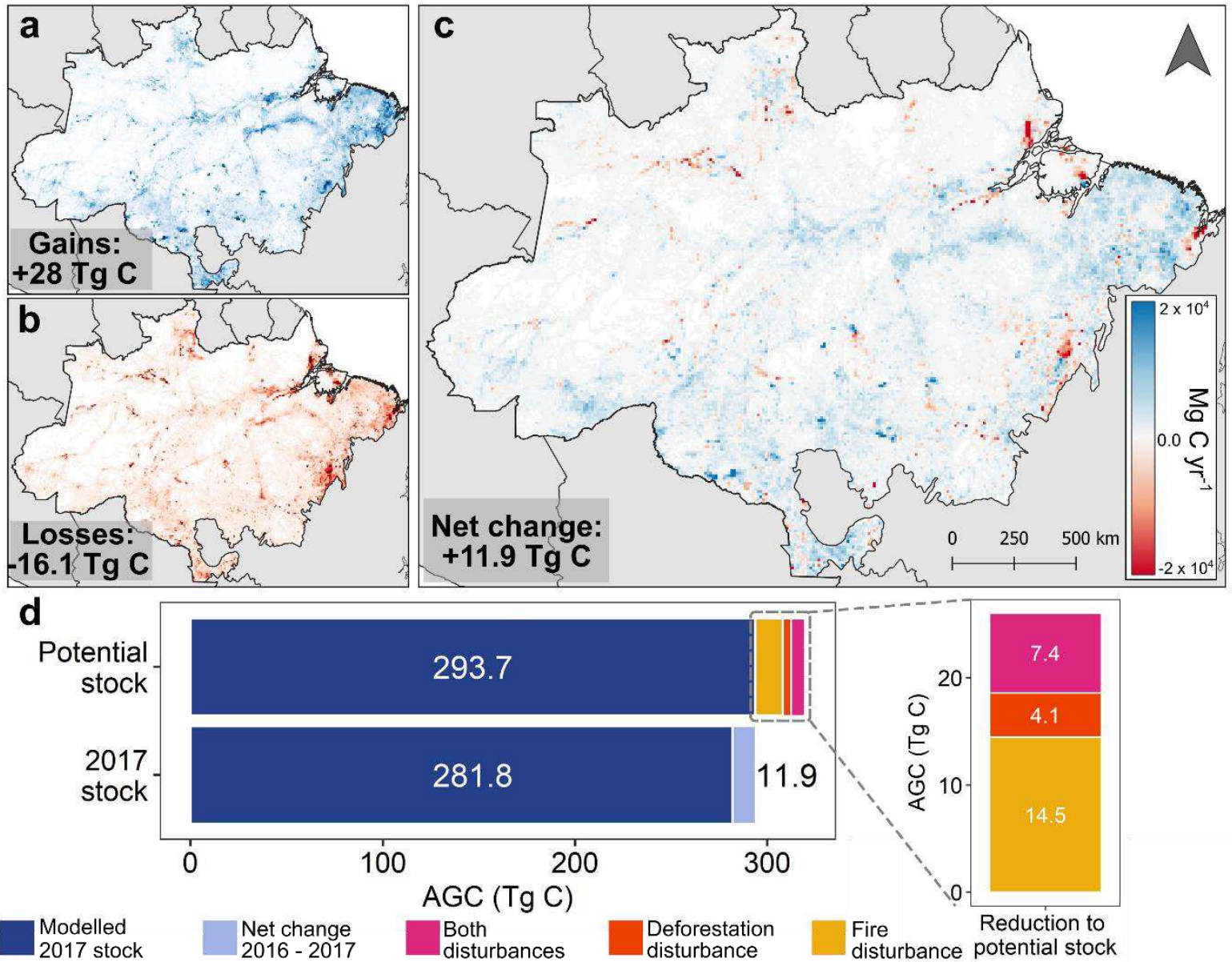

Figure 4 |The modelled and potential secondary forest 2017 carbon stock. This includes the AGC gains from forests growth (a) and losses from forest loss (b) to provide a net change in the carbon stock between 2016 and 2017 per $0.1^{\circ}$ grid (c) as well as the potential total carbon stock in 2017 if none of the forest experienced any kind of disturbance (d).

a

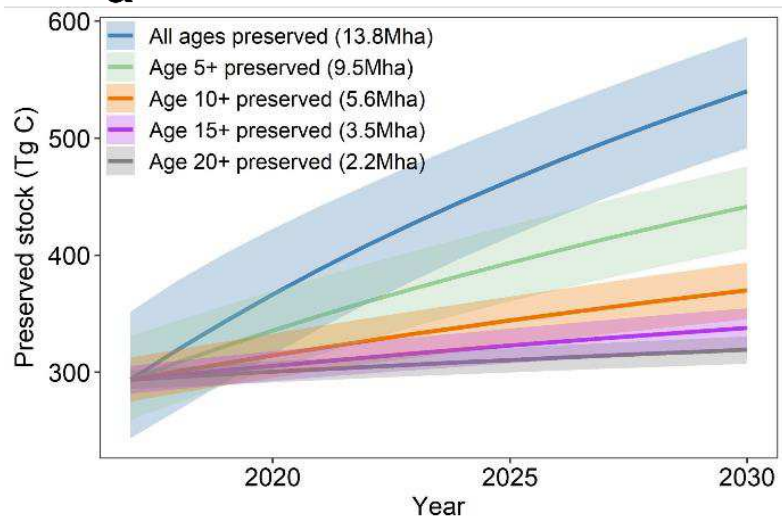

b

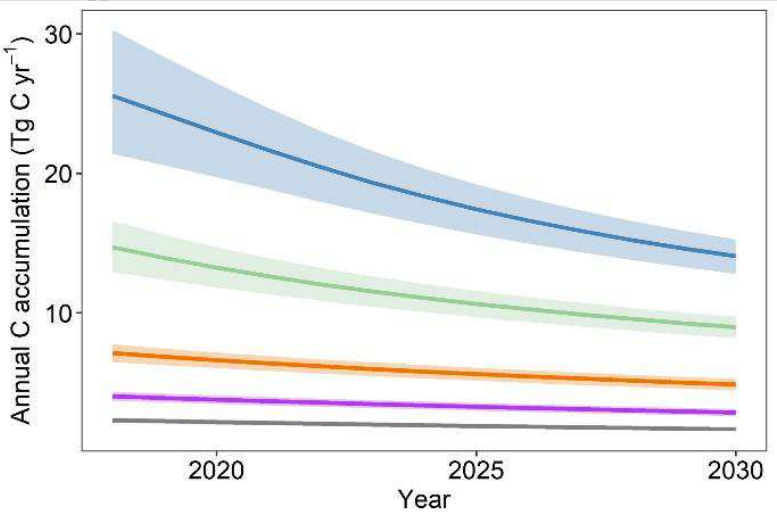

Figure 5 | The future carbon stock and carbon accumulation in Amazonian secondary forests. The changes to the carbon stock (a) and annual carbon accumulation (b) are calculated for the coming decade, considering different scenarios of preservation. Shading denotes the $95 \%$ confidence interval of the regrowth model. 
In this study, we quantified the impact of environmental and anthropogenic disturbance drivers on low SW radiation observed in western Amazonia $\left(\sim 163.6 \mathrm{Wm}^{-2}\right)$ (Supplementary Figure 7 ) having the highest regrowth rates ranging between $2.4 \pm 0.8$ to $3.0 \pm 1.0 \mathrm{Mg} \mathrm{C} \mathrm{ha}^{-1} \mathrm{yr}^{-1}$. These estimates are similar to the previous estimates of $2.95 \pm 0.4$ and $3.05 \pm 0.5 \mathrm{Mg} \mathrm{C}^{-1} \mathrm{yr}^{-111,12}$. The higher estimated regrowth rates in areas of lower SW radiation is likely linked to higher cloud cover resulting in more diffuse radiation and lower vapour pressure deficit (Figure 1 and 3a). Diffuse radiation can penetrate deeper into closed forest canopies than direct shortwave radiation and enhance productivity and thereby carbon sequestration $^{13,35}$, whilst a lower vapour pressure deficit encourages leaf stomata to remain open, maximising productivity and thereby regrowth ${ }^{36}$.

Additionally, there are synergies between the drivers that influence the regrowth of SF (Figure 1). For example, in the South-East and Northern regions, regrowth rate is approximately $50 \%$ lower compared to western regions, likely due to the hydro-climatic conditions which reduce growth (low precipitation, $\sim 1913 \mathrm{~mm} \mathrm{yr}^{-1}$; very high MCWD, -325.5 $\mathrm{mm} \mathrm{yr}^{-1}$; moderate $\mathrm{SW}$ radiation, $\sim 181.7 \mathrm{Wm}^{-2}$ ). In turn, this results in an environment that is drier and more susceptible to burning, reducing regrowth rates even further (Figure 3d). Previous field-based studies have estimated the reduction in regrowth due to fire to be $50 \%$ (reducing from 3.2 to $1.7 \mathrm{Mg} \mathrm{C} \mathrm{ha}^{-1} \mathrm{yr}^{-1}$ ) ${ }^{16}$, which is similar to the average reduction estimated in our study (40\%). With our method we were able to provide additional information disaggregated by regions, showing that the regrowth rate in the North-Western and South-Western regions SF exposed to fire were $20 \%$ and $60 \%$ lower, respectively, compared to non-disturbed SF (Supplementary Table 9). The interactions between the drivers and the impact this has on the regrowth rates has never been spatially quantified until now.

Across Amazonia, fire and repeated deforestations were evaluated as the least important drivers (Figure 1g). Nonetheless, several other studies have shown that the importance of these drivers is not negligible ${ }^{16,37,38}$, and that the perceived lack of importance may be a local-scale artefact which our model cannot account for in the large environmental regions identified in this study (Figure 2a). Environmental drivers act on regional scales and influence forest type and species physiology. Fire and deforestation act on the local scale by reducing the seed bank, natural biodiversity, soil nutrient, and water availability, which can cause arrested succession (a disturbance preventing the natural successional growth) ${ }^{39}$. Indeed, we see evidence of arrested succession in the slow growth (up to $80 \%$ lower) and early plateau in AGC (12 - 25 years) in some regions that experienced successive disturbance and suboptimal environmental conditions (Figure $3 b$ and d; Supplementary Table 9). Regions subjected to burning and repeated deforestations that do not reach AGC levels equivalent to those of old-growth forests, highlight that both drivers are much more influential than our model can infer. Additionally, the spatial extent of fire disturbance is likely to be more widespread than presented in our study, as the remote sensing product, based on automatic detection, used in this study underestimates burnt area by $\sim 25 \%$ compared to manual photointerpretation methods ${ }^{40}$.

Given that our study consisted of 32 years of secondary forest data and one year of AGC data, each of which has associated uncertainties, we take caution with the regrowth rates modelled much beyond this period (see Supplementary Discussion for additional explanation). However, the results highlight the potential threat that an alternative stable state, of low AGC in older SF, could arise if they are not managed sustainably and experience successive disturbance ${ }^{41,42}$. Even in the regions of no disturbance and favourable environmental conditions, where SF AGC recovered to old-growth forest levels up to 4 times more rapidly, we estimated the minimum time taken to reach old-growth forest AGC to be $\sim 100$ years (Supplementary Tables 8 and 9). SF will therefore never replace old-growth forests on policyrelevant timescales, stressing the continued need to conserve existing old-growth forests (Supplementary Table 9) $)^{43}$. 
Furthermore, the threat of forest water deficit and, consequently, drought-induced fire disturbances are predicted to increase into the $21^{\text {st }}$ century due to ongoing climate change ${ }^{44}$. If this kind of climatescenario arises, the reduced regrowth rate of the secondary forest as seen in the South-East region in our analysis is likely to be more widespread and severe (Figures 1-3). This would threaten the permanence of the carbon sequestration potential of SF as we have calculated in this study ${ }^{17}$. Given that some degree of $21^{\text {st }}$ century climate change is now already out of human control, it is imperative to limit anthropogenic disturbances, such as fire and deforestation. Overall, we estimate these disturbances to have contributed to an 8\% reduction in the total potential 2017 carbon stock (Figure 4d), with the highest relative reduction (11\%) in North-Eastern Amazonia (Supplementary Figure 12). This has important implications for policies concerning human-induced burning regimes as well as the deforestation of secondary forests. Our analysis has shown that avoiding these actions increases the regrowth potential of SF and will ultimately help Brazil to achieve its NDC goals of reducing net national emissions by $37 \%$ in 2025 and $43 \%$ in 2030 compared to 2005 levels $^{7}$. This amount is equivalent to net emissions of $354 \mathrm{Tg} \mathrm{C} \mathrm{yr}^{-1}\left(1.3 \mathrm{GtCO}_{2} \mathrm{e} \mathrm{yr}^{-1}\right)$ and 327Tg C $\mathrm{yr}^{-1}\left(1.2 \mathrm{GtCO}_{2} \mathrm{e} \mathrm{yr}^{-1}\right)$, respectively. We model the future carbon sequestration rate by preserving all standing SF and find that the annual carbon accumulation would be equivalent to providing an additional $5 \pm 1 \%$ reduction to the 2025/2030 emissions target (Figure 5b). Conversely, if only SF older than 20 years in 2017 were preserved, the additional mitigation potential would reduce to less than $1 \%$ (Figure $5 \mathrm{~b}$ ). The modelling shows that various levels of SF preservation can contribute significantly to Brazil reaching its NDC targets. However, these estimates assume that future rates of deforestation in SF and old-growth forests remain sustainable.

In recent years, emissions from deforestation have accelerated to levels approximately equal to the beginning of the $21^{\text {st }}$ century $\left(170{\mathrm{Tg} \mathrm{C} \mathrm{yr}^{-1}}^{-1} 2019^{15,45}\right)$. Assuming all SF standing in 2017 still stood in 2019 , the annual SF carbon accumulation would have offset $14 \pm 1 \%$ of the gross carbon emissions from Amazonian deforestation in that year. The climate mitigation of SF within the Brazilian NDC for the next decade can therefore only be realised if a sustainable management of all forests is achieved now.

\section{Conclusions}

Our model results have the potential to benefit both the carbon modelling and carbon-policy communities to help understand the regional variations of regrowth under different drivers. The carbon modelling community will benefit from the ability to spatially monitor carbon dynamics, which can be incorporated into models and scenarios of land cover and climate change. Additionally, the methods used in this study can be developed further to include other important variables that influence regrowth. This includes variables such as the type of previous land use practises (livestock, agriculture, and forestry) and the period of active land use before abandonment. For instance, SF regrow $38 \%$ faster on land used for agriculture than those for cattle pastures ${ }^{37,46}$. Our models will benefit carbon-policy communities by helping to assess locations for restoring and reforesting 12Mha of forests, as proposed by Brazil's NDC, that would maximise regrowth and thereby be most beneficial to mitigating climate change. This includes areas with limited anthropogenic disturbances, which will minimise forest restoration and thereby costs of implementation and conservation. Additionally, the results can be used to improve monitoring under the Reducing Emissions from Deforestation and Degradation (REDD+) scheme. This approach would not be limited to Amazonia and could be applied in other countries where field data may be limited.

A wide range of remote sensing products can be used to monitor SF change, and more are in development. Large-scale single-date AGC products, such as the ESA-CCI, allows us to apply spacefor-time substitution techniques and improve our understanding of forest growth and potential. However, the application of these methods for predicting future carbon stocks will bring large uncertainties without the ability to validate model results against temporal products. This could be achieved in future research using high spatial and temporal resolution orbital LiDAR data derived from 
GEDI (Global Ecosystem Dynamics) or IceSat-2 (Ice, Cloud and land Elevation Satellite) ${ }^{47}$ as well as the continuous production of the ESA-CCI product used in this study. With the use of temporal products, we can better understand and monitor the current and future role of these forests in the carbon cycle and as climate mitigation strategies on potentially a global scale.

Our study has quantified the varied and complicated regrowth rates of SF across Amazonia influenced by multiple drivers across Amazonia. Given the uncertain and potentially threatened status of oldgrowth forest sinks due to ongoing climate change ${ }^{4}$, it is imperative to limit human-induced fire and deforestation disturbance in both old-growth and SF. By preserving the remaining old-growth forest stock and sustainability managing SF we can maintain and increase the carbon sink of this globally important biome and help it to achieve its climate mitigation potential.

Methods

\section{7}

\section{Identifying areas of Secondary forest and their ages}

The underlying product for this research was the land-use and land-cover product (MapBiomas Collection 3.1), available for the whole of Brazil for the years 1985 to $2017^{24}$. The dataset is based on Landsat image classification, mapping annual land-use and land-cover at 30m spatial resolution. We follow a very similar methodology applied by Nunes et al. ${ }^{10}$ and Silva Junior et al. ${ }^{18}$. to identify areas of secondary forest (SF) and determine their respective ages. We reclassified forest land and all land under human use to values of 1 and 0 , respectively and tracked, when a conversion from anthropogenic (0) to forest land (1) took place. Consecutive years following this transition in which a forest remained forest, were considered to be SF and used to estimate their respective ages (in years). Ages ranged from 1 to 32 years since the MapBiomas product (v3.1) is available for the period 1985 to 2017. Any forest land pixels that did not undergo a transition during this period were considered an old-growth forest. A limitation is therefore that this method cannot classify forests as secondary forests that were deforested and regrew before 1985. If an area of SF was deforested during the period of analysis, we disregarded the area as SF and only began calculating the age again if a conversion from 0 to 1 took place. From this we also calculated the number of times an area of SF was deforested during the period 1986 to 2016.

Previous research has shown that the MapBiomas product misclassifies perennial crops such as oil palm plantations ${ }^{10}$ and other plantation forests as natural forests (Supplementary Figure 2). To remove misclassified areas, we used the latest land cover data of another, widely used Brazilian land cover product, TerraClass- $2014^{9}$. Finally, we excluded areas of SF (within a $3 \mathrm{~km}$ radius) that overlay field inventory sites of SF for cross validation of our method (Supplementary Figure 10; Supplementary Table 10).

\section{Modelling carbon sequestration with different drivers}

To model the regrowth of SF we applied a space-for-time substitution method. Instead of tracking the associated Aboveground Carbon (AGC) regrowth over time, the regrowth was estimated by considering the available ages of the standing SF in 2017 and the associated AGC at the same time. Here we explain the methods used to determine SF AGC using the ESA-CCI Aboveground Biomass (AGB) product $(100-m)$ for the year $2017^{22}$ (see Supplementary Discussion for further details). All analysis was carried out in the units of the original product (AGB) but expressed as AGC by assuming a 2:1 ratio of biomass to carbon ${ }^{23}$. The ESA-CCI AGB product was only released in late 2019 and was in its early phases of development at the time of use. However, given that its spatial resolution was high enough to separate areas of only SF and its recent acquisition warranted its use for this research. Only areas of SF greater than $9,000 \mathrm{~m}^{2}$ were considered for further analysis, an area approximately equal to 1 pixel of the ESACCI product. The SF map was laid over the AGC data and the modal AGC was extracted for each SF patch. We then aggregated the AGC values by the age of SF and used the median AGC value for each 
age in further analysis. We applied a bias correction to the median AGC values, subtracting the smallest median value from all values to shift the data to begin at or near $0 \mathrm{Mg} \mathrm{Cha}^{-1} \mathrm{AGC}$ for a 1-year old SF.

Following this, we used six remote sensing products of driving variables widely accepted to influence regrowth of forests. The data products included four environmental drivers $(1-4)$ and two anthropogenic disturbance drivers (5 - 6): (1) Mean annual downward shortwave radiation (for the period 1985 to 2017$)^{25}$, (2) Mean annual precipitation (for the period 1985 to 2017) ${ }^{26}$, (3) the mean Maximum Cumulative Water Deficit (MCWD) (for the period 1985 to 2017) (48 $^{4}$ (4) Soil Cation Concentration $^{29}$, (5) Annual burned areas (between 2001 and 2017) (30 $^{30}$ and (6) Number of times a SF area was deforested between 1987 and 2017 (repeated deforestations) (this study). These products all have different spatial resolutions (Supplementary Table 1) and so had to be resampled to the size of SF pixels (30-m spatial resolution) using the "resample" package in the Geographic Information System programme, ArcMap10.6. We calculated the key zonal statistics of these variables such as the mean value of the driver affecting a specific area of SF.

The drivers were then grouped according to numerical limits, such as the $25^{\text {th }}, 50^{\text {th }}$ and $75^{\text {th }}$ percentiles. We then modelled the AGC for the age of SF under these groupings using the commonly used Chapman-Richard model for regrowth ${ }^{49}$ :

$$
Y_{t}=A\left(1-e^{-k t}\right)^{c} \pm \varepsilon ; A, k \text { and } c>0
$$

where $Y_{t}$ refers to the AGC at age $t$; A is the AGC asymptote or the AGC of the old-growth forest; $k$ is a growth rate coefficient of $Y$ as a function of age; $c$ is a coefficient that determines the shape the growth curve; and $\varepsilon$ is an error term. We assumed that after a given amount of time, the AGC could return to levels equivalent to old-growth forests, and reach a precalculated asymptote. As such, we extracted the median, bias-corrected AGC value of old-growth forests under each variable condition from the ESACCI AGC product to represent the value of the asymptote. From this, we could also determine if and when the SF AGC regrowth models would reach those equivalent to old-growth forest levels. Forcing the models to "fit" to an expected value for the asymptote value naturally increases the error of our model, partly due to heterogeneity in old-growth forest values within each variable condition.

\section{Determining the importance of each driver}

We used a random forest model to assess which of the drivers used in this research were the most important in influencing the regrowth of SF. To maximise computational speed and to account for any biases in the products used we applied a stratified random sample equating to $2 \%$ of the data into the random forest model $(n=50,000)$. This sample size was more than the minimum number of samples needed $(1,000=0.04 \%)$ to ensure results would be within the $95 \%$ confidence interval with a sampling error of $5 \%$ using a multinomial function ${ }^{50}$. We carried out all analysis using the conditional random forest model "cforest" available in predictive model package "caret" for the statistical software "R"(v4.0.2) $)^{51,52}$. The "cforest" random forest model provides more accurate importance estimates compared to more traditional random forest models such as "randomForest" when the dataset includes both continuous (e.g. precipitation) and categorical data (e.g. burnt, not burnt) data ${ }^{53}$. We used $80 \%$ of the sampled data for training the model and the remaining $20 \%$ to test the model. From this analysis we estimated the "Permutation importance" also known as the "Mean Decrease in Accuracy" (as a percentage) for each variable, which indicates the most important variable in terms ranking (higher value meaning more importance to the determine the value of AGC). We show the variable importance relative to SF age, identified as the most important variable in influencing AGC. The interpretation of the results should be limited to the rankings and not the absolute values of the percentages ${ }^{54}$.

\section{Representing spatial patterns of secondary forest regrowth}

We created a regional classification based on the three most important environmental variables driving regrowth. We used an unsupervised K-means cluster analysis to group Amazonia into regions based on 
similarities between the SF in terms of the drivers' variability. We then subclassified each region based on the type of disturbance (fire and/or deforestation) experienced by the SF. The aim of this was to show areas of SF that experience similar conditions and the effect this has on regrowth in a spatially explicit manner. We developed 16 regional-models of regrowth and included the median, bias-corrected AGC value for old-growth forest in each of the regions as the asymptote of the models. Using the random forest model, we again determined the importance of drivers for each region, as described in the previous section.

\section{Estimating 2017 carbon stock and future carbon sinks}

We estimated the 2017 carbon stock by applying the corresponding regional models to all pixels initially identified as SF with respect to the pixel age, and whether the pixel experienced any disturbances. From this we were able to estimate the carbon stock in 2017 for all SF and the net carbon change from 2016 to 2017. We also considered an alternative scenario in which no forest disturbance occurred during regrowth by applying the no-disturbance models to the corresponding regions. In this alternative scenario, we were able to calculate the resulting potential 2017 carbon stock, and associated reduction due to disturbances. Finally, by aging the standing SF in 2017, we modelled the carbon stock and annual carbon accumulation for the next decade considering different scenarios of SF preservation: (1) all forests; (2) forest with ages 5+; (3) forest with ages 10+; (4) forest with ages 15+; (5) forest with ages $20+$ years.

\section{Data and Code Availability}

The original data used in this study are all publicly available from their sources (see references). Processed data, products and codes produced in this research are available from the corresponding author upon reasonable request. The regrowth models can be built by users using Equation 1 and information provided in Supplementary Tables 8 and 9.

\section{Acknowledgements}

V.H.A.H was supported by a NERC GW4+ Doctoral Training Partnership studentship from the Natural Environment Research Council (NE/L002434/1). R.D, was supported by CNPq (National Council for Scientific and Technological Development) Grant no. 160286/2019-0, and FAPESP (São Paulo Research Foundation) Grant no. 2019/21662-8. H.L.G.C was supported by FAPESP (2018/14423-4). C.T.A was partially supported by CNPq (140502/2016-5). S.S and T.M.R were partly supported by the European Space Agency Climate Change Initiative ESA-CCI RECCAP2 project (ESRIN/ 4000123002/18/I-NB), and the Newton Fund through the Met Office Climate Science for Service Partnership Brazil (CSSP Brazil). The latter provided V.H.A.H travel support during this study. C.T.A was partially supported by CNPq (140502/2016-5). C.H.L.S.J was supported in part by CAPES (Coordenação de Aperfeiçoamento de Pessoal de Nível Superior - Brazil) - Finance Code 001. W.C. was supported in part by CAPES - Finance Code 001 as well as by CNPq (140261/2018-4). J.I.H was supported in part by funding from NERC GGRiLs-Gaps, NERC DARE-UK and EU-FP7 VERIFY. T.C. was supported in part by a NERC grant. M.A. was supported by a Royal Society Newton Advanced Fellowship (NAF/R1/180405). L.O.A. was supported by the Inter-American Institute for Global Change Research (IAI) (process: SGP-HW 016), FAPESP (process 2016/02018-2, 19/05440-5) and CNPq (442650/2018-3, 441949/2018-5). L.E.O.C.A. was supported by CNPq (processes 305054/20163 and 442371/2019-5) and FAPESP (process 2018/15001-6; ARBOLES Project) Finally, we are thankful to the developers of all the products used in this study for providing free, open-access datasets.

\section{Author contributions}

V.H.A.H and L.E.O.C.A developed the concept and main methodological process. V.H.A.H carried out the data analysis and wrote the initial manuscript draft with additional support from R.D, H.L.G.C and T.M.R. H.L.G.C compiled the field inventory data and provided methodological suggestions. R.D, 
H.L.G.C, T.M.R, C.T, C.S and W.C provided codes that were adapted for this research. J.H, S.S, T.H, T.M.R, M.A and L.O.A provided vital comments on the data analysis and scientific support throughout the study. All authors discussed results and provided comments during the preparation of the manuscript.

\section{Competing interest declaration}

The authors declare no competing interests.

\section{Additional information}

Supplementary Information is available for this paper.

Correspondence and request for material should be addressed to V.H.A.H.

Reprints and permissions information is available at www.nature.com/reprints

\section{References}

1. Grassi, G. et al. The key role of forests in meeting climate targets requires science for credible mitigation. Nat. Clim. Chang. 7, 220-226 (2017).

2. Baccini, A. et al. Estimated carbon dioxide emissions from tropical deforestation improved by carbon-density maps. Nat. Clim. Chang. 2, 182-185 (2012).

3. Avitabile, V. et al. An integrated pan-tropical biomass map using multiple reference datasets. Glob. Chang. Biol. 22, 1406-1420 (2016).

4. Hubau, W. et al. Asynchronous carbon sink saturation in African and Amazonian tropical forests. Nature 579, 80-87 (2020).

5. Song, X. P., Huang, C., Saatchi, S. S., Hansen, M. C. \& Townshend, J. R. Annual carbon emissions from deforestation in the Amazon basin between 2000 and 2010. PLoS One 10, 1-21 (2015).

6. Pan, Y. et al. A Large and Persistent Carbon Sink in the World's Forests. Science (80-. ). 333, 988-993 (2011).

7. Ministério do Meio Ambiente (MMA). REDD+ and Brazil's Nationally Determined Contribution. http://redd.mma.gov.br/en/redd-and-brazil-s-ndc (2016).

8. Bongers, F., Chazdon, R. L., Poorter, L. \& Peña-Claros, M. The potential of secondary forests. Science (80-. ). 348, 642-643 (2015).

9. Almeida, C. A. de et al. High spatial resolution land use and land cover mapping of the Brazilian Legal Amazon in 2008 using Landsat-5/TM and MODIS data. Acta Amaz. 46, 291-302 (2016).

10. Nunes, S., Jr. Oliveira, L., Siqueira, J., Morton, D. C. \& Souza, C. M. Unmasking secondary vegetation dynamics in the Brazilian Amazon. Environ. Res. Lett. 0-27 (2020).

11. Poorter, L. et al. Biomass resilience of Neotropical secondary forests. Nature 530, 211-214 (2016).

12. Requena Suarez, D. et al. Estimating aboveground net biomass change for tropical and subtropical forests: Refinement of IPCC default rates using forest plot data. Glob. Chang. Biol. 25, 3609-3624 (2019).

13. Mercado, L. M. et al. Impact of changes in diffuse radiation on the global land carbon sink. Nature 458, 1014-1017 (2009).

14. Chazdon, R. L. et al. Carbon sequestration potential of second-growth forest regeneration in the Latin American tropics. Sci. Adv. 2, (2016). 
15. Aragão, L. E. O. C. et al. 21st Century drought-related fires counteract the decline of Amazon deforestation carbon emissions. Nat. Commun. 9, (2018).

16. Zarin, D. J. et al. Legacy of fire slows carbon accumulation in Amazonian forest regrowth. Front. Ecol. Environ. 3, 365-369 (2005).

17. Anderegg, W. et al. Climate-driven risks to the climate mitigation potential of forests. Science (80-. ). 1327, (2020).

18. Silva Junior, C. H. L. et al. Benchmark maps of 33 years of secondary forest age for Brazil. Sci. Data 7, 269 (2020).

19. Yang, Y., Saatchi, S., Xu, L., Keller, M. \& Corsini, C. R. Interannual Variability of Carbon Uptake of Secondary Forests in the Brazilian Amazon ( 2004 - 2014 ) Global Biogeochemical Cycles. 1-14 (2020) doi:10.1029/2019GB006396.

20. Vieira, I. C. G., Gardner, T., Ferreira, J., Lees, A. C. \& Barlow, J. Challenges of governing second-growth forests: A case study from the Brazilian Amazonian state of Pará. Forests $\mathbf{5}$, 1737-1752 (2014).

21. Wang, Y. et al. Upturn in secondary forest clearing buffers primary forest loss in the Brazilian Amazon. Nat. Sustain. (2020) doi:10.1038/s41893-019-0470-4.

22. Santoro, M. \& Cartus, O. ESA Biomass Climate Change Initiative (Biomass_cci): Global datasets of forest above-ground biomass for the year 2017, v1. Centre for Environmental Data Analysis. 2019 https://catalogue.ceda.ac.uk/uuid/bedc59f37c9545c981a839eb552e4084.

23. IPCC. Chapter 4 Forest Land. in IPCC Guidelines for National Greenhouse Gas Inventories (eds. Aalde, H. et al.) vol. 4 Agricult 1-29 (2006).

24. Mapbiomas Brasil. Project MapBiomas - Collection 3.1 of Brazilian Land Cover and Use Map Series. https://mapbiomas.org/ (2018).

25. TerraClimate - Climatology Lab. http://www.climatologylab.org/terraclimate.html.

26. Funk, C. et al. The climate hazards infrared precipitation with stations - A new environmental record for monitoring extremes. Sci. Data 2, 1-21 (2015).

27. Anderson, L. O. et al. Vulnerability of Amazonian forests to repeated droughts. Philos. Trans. R. Soc. B Biol. Sci. 373, (2018).

28. Phillips, O. L. et al. Drought Sensitivity of the Amazon Rainforest. 323, 1344-1347 (2009).

29. Zuquim, G. et al. Making the most of scarce data: Mapping soil gradients in data-poor areas using species occurrence records. Methods Ecol. Evol. 10, 788-801 (2019).

30. Didan, K. MOD13Q1 MODIS/Terra Vegetation Indices 16-Day L3 Global 250m SIN Grid V006. NASA EOSDIS Land Processes DAAC. http://doi.org/10.5067/MODIS/MOD13Q1.006. USGS vol. 5 2002-2015 (2015).

31. Johnson, C. M., Vieira, I. C. G., Zarin, D. J., Frizano, J. \& Johnson, A. H. Carbon and nutrient storage in primary and secondary forests in eastern Amazônia. For. Ecol. Manage. 147, 245-252 (2001).

32. Moran, E. F. et al. Moran et al, 2000 - former land use effects on reg forest - BZ.pdf VN readcube.com. For. Ecol. Manage. 139, 93-108 (2000).

33. Alves, D. S. et al. Biomass of primary and secondary vegetation in Rondônia, Western Brazilian Amazon. Glob. Chang. Biol. 3, 451-461 (1997).

34. MCT. Third National Communication of Brazil to the United Nations Framework Convention on Climate Change - Volume III. vol. III (2016). 
35. Roderick, M. L., Farquhar, G. D., Berry, S. L. \& Noble, I. R. On the direct effect of clouds and atmospheric particles on the productivity and structure of vegetation. Oecologia 129, 21-30 (2001).

36. Lange, O. L., Lösch, R., Schulze, E. D. \& Kappen, L. Responses of stomata to changes in humidity. Planta 100, 76-86 (1971).

37. Wandelli, E. V. \& Fearnside, P. M. Secondary vegetation in central Amazonia: Land-use history effects on aboveground biomass. For. Ecol. Manage. 347, 140-148 (2015).

38. Uhl, C., Buschbacher, R. \& Serrão, E. A. . Abandoned Pastures in Eastern Amazonia . I . Patterns of Plant Succession. J. Ecol. 76, 663-681 (1988).

39. Jakovac, C. C., Peña-Claros, M., Kuyper, T. W. \& Bongers, F. Loss of secondary-forest resilience by land-use intensification in the Amazon. J. Ecol. 103, 67-77 (2015).

40. Morton, D. C. et al. Mapping canopy damage from understory fires in Amazon forests using annual time series of Landsat and MODIS data. Remote Sens. Environ. 115, 1706-1720 (2011).

41. Hirota, M., Holmgren, M., van Nes, E. H. \& Scheffer, M. Global Resilience of Tropical Forest. Science (80-. ). 334, 232-235 (2011).

42. Scheffer, M. et al. Anticipating Critical Transitions. 338, (2012).

43. Elias, F. et al. Assessing the growth and climate sensitivity of secondary forests in highly deforested Amazonian landscapes. Ecology 101, (2020).

44. Aragão, L. E. O. C. et al. Environmental change and the carbon balance of Amazonian forests. Biol. Rev. 89, 913-931 (2014).

45. PRODES. TerraBrasilis - Taxas anuais de sesmatamento na Amazônia Legal Brasiliera. 2020 http://terrabrasilis.dpi.inpe.br/app/dashboard/deforestation/biomes/legal_amazon/rates.

46. Fearnside, P. M. \& Guimarães, W. M. Carbon Uptake By Secondary Forests in Brazilian Amazonia. 80, 35-46 (1996).

47. Dubayah, R. et al. The Global Ecosystem Dynamics Investigation: High-resolution laser ranging of the Earth's forests and topography. Sci. Remote Sens. 1, 100002 (2020).

48. Aragão, L. E. O. C. et al. Spatial patterns and fire response of recent Amazonian droughts. Geophys. Res. Lett. 34, 1-5 (2007).

49. Richards, F. J. A flexible growth function for empirical use. J. Exp. Bot. 10, 290-301 (1959).

50. Congalton, Russell, G. \& Green, K. Assessing the Accuracy of Remotely Sensed Data: Principles and Practices. vol. 25 (CRC Press, 2009).

51. Kuhn, M. et al. Caret: 6.0-71., Classification and Regression Training. R package version. (2016).

52. R Development Core Team: R: A Language and Environment for Statis- tical Computing. (2008).

53. Strobl, C., Boulesteix, A. L., Zeileis, A. \& Hothorn, T. Bias in random forest variable importance measures: Illustrations, sources and a solution. BMC Bioinformatics 8, (2007).

54. Strobl, C., Boulesteix, A. L., Kneib, T., Augustin, T. \& Zeileis, A. Conditional variable importance for random forests. BMC Bioinformatics 9, 1-11 (2008). 


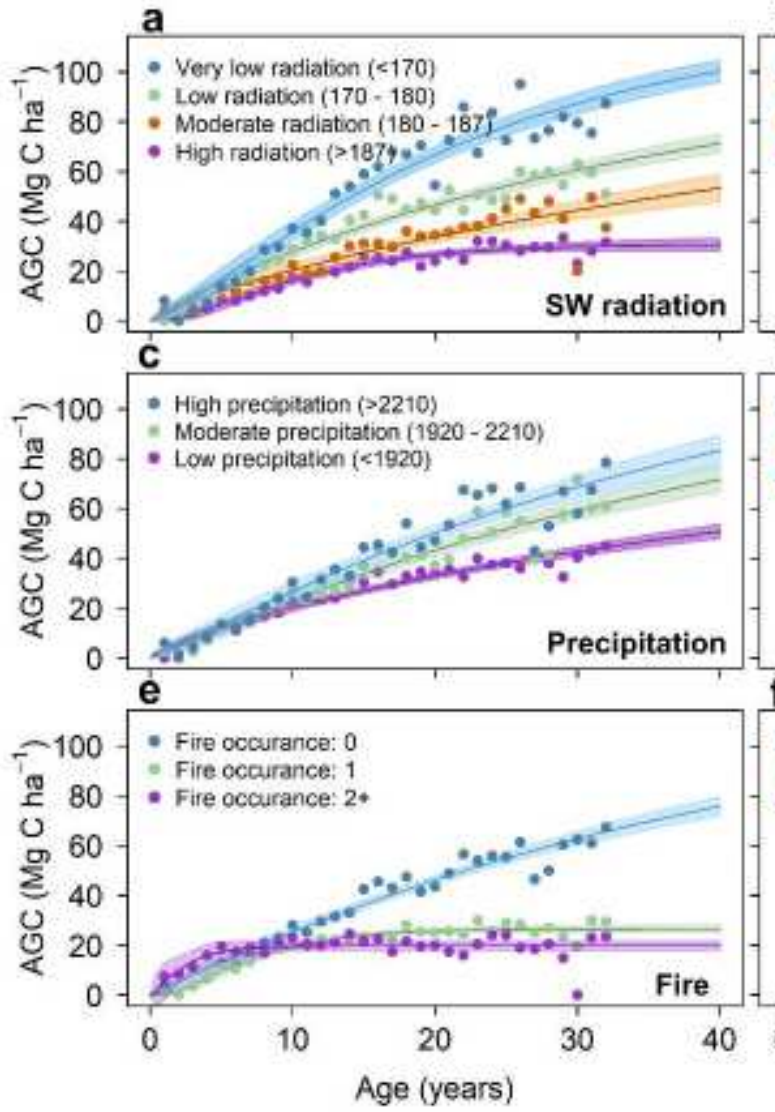

b

- Very low MCWD (>-180)

- Low MCWD (-180 - -277)

- Moderate MCWD (-277 - -350

- Very high MCWD (<-350)

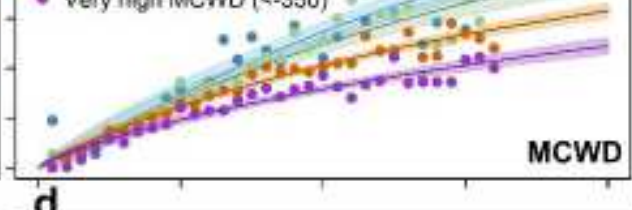

- High SCC $(>0.8)$

Moderate SCC $(0,5-0.8)$

- Low SCC (0.3-0.5)

- Very low SCC $(<0.3)$
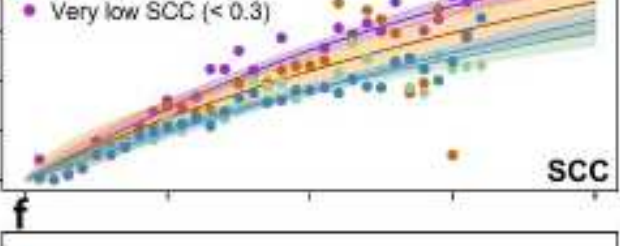

- Deforested: 1

- Deforestedi 2

- Deforested: 3 .

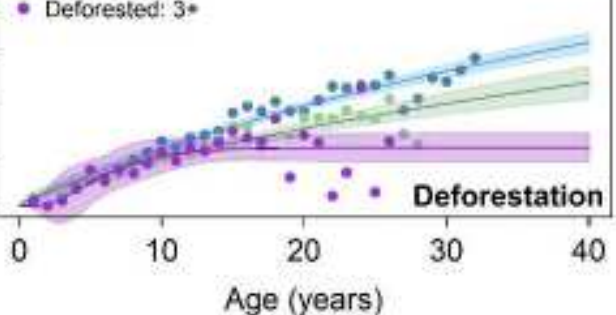

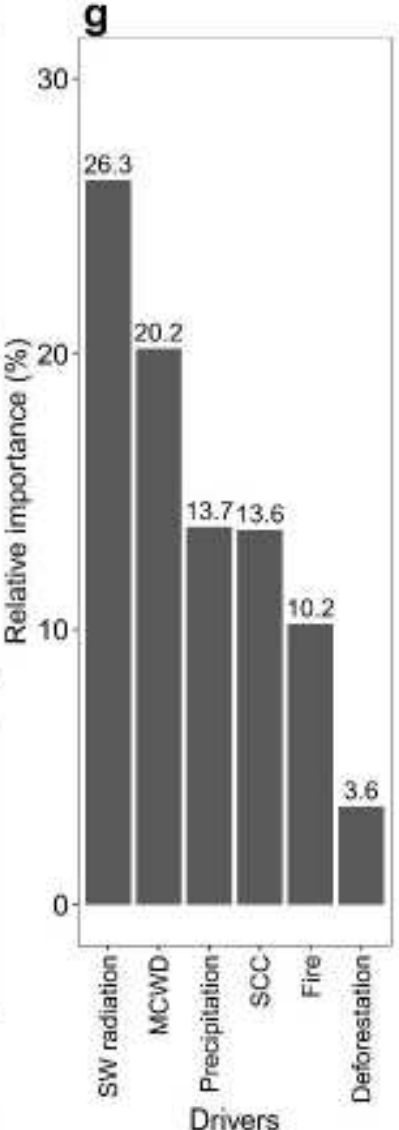

\section{Figure 1}

Secondary forest carbon accumulation with increasing age under different driving conditions. Drivers are (a) Annual mean downward shortwave radiation (Wm-2), (b) Maximum Cumulative Water Deficit (MCWD; mm yr-1), (c) Annual mean precipitation (mm yr-1), (d) Soil Cation Concentration (SCC; cmol(+) kg-1), (e) Fire occurrences between 2001 and 2017, (f) Number of repeated deforestations between 1985 and 2017 , where 1 refers the initial conversion from old-growth forest to other land. The bar graph (g) shows the importance of the drivers (a-f) in influencing AGC relative to the importance of Forest age $(100 \%$ - not shown in figure). Shading in (a-f) denotes the 95\% confidence interval of the models, based on the median value of the initial data for each age - dots in figures. 

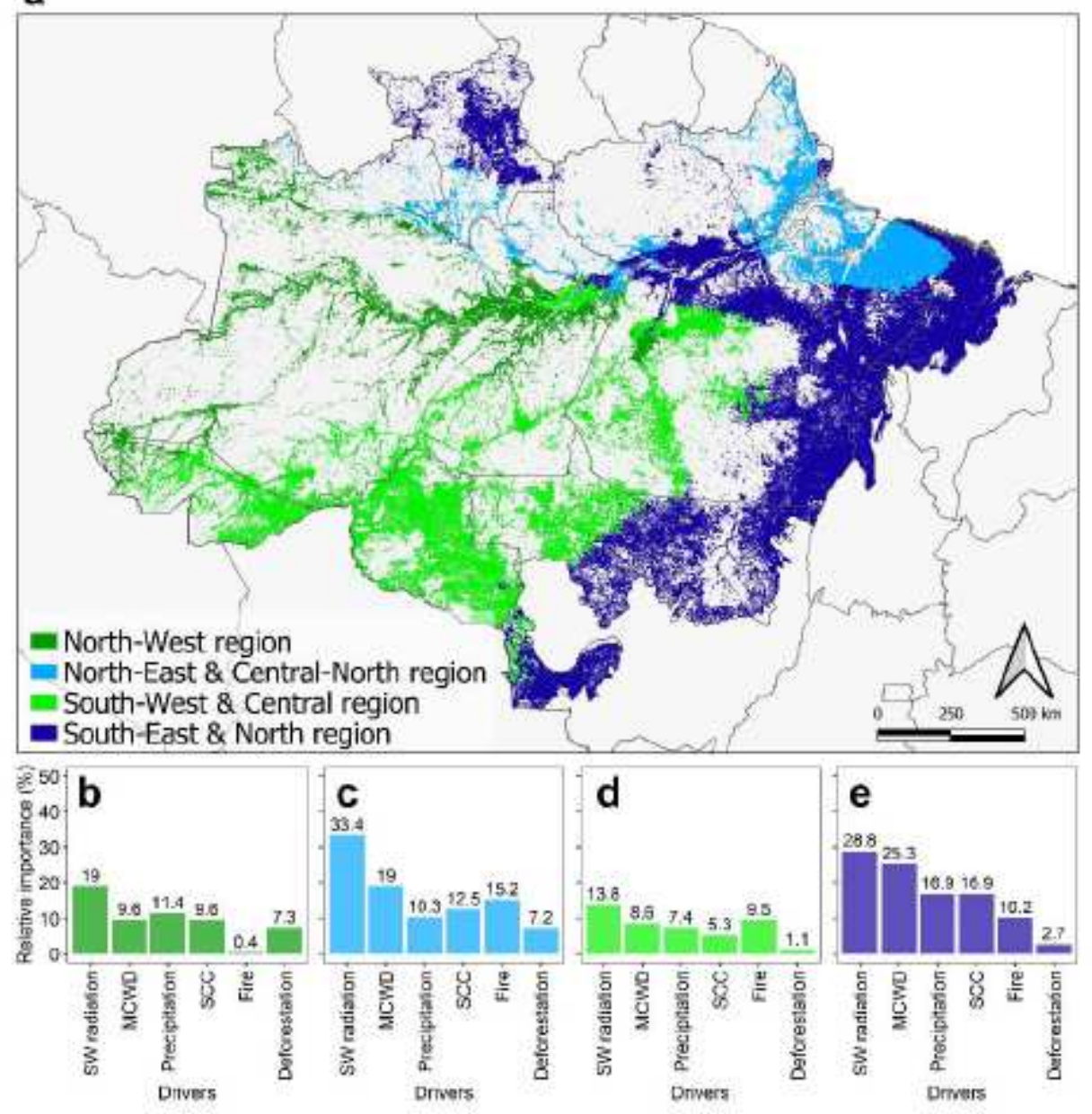

Figure 2

Secondary Forests grouped by climatological similarities. Regions are grouped according to similarities in Maximum Cumulative Water Deficit (MCWD), annual average downward shortwave radiation and annual average precipitation (a). The importance of different drivers relative to Forest age is shown (most important $-100 \%$, not shown) for the North-West region (b), North-East and Central-North region (c), South-West and Central region (d), South-East and North region (e). See Supplementary Table 9 for quantitative interpretations of the regions. 
a

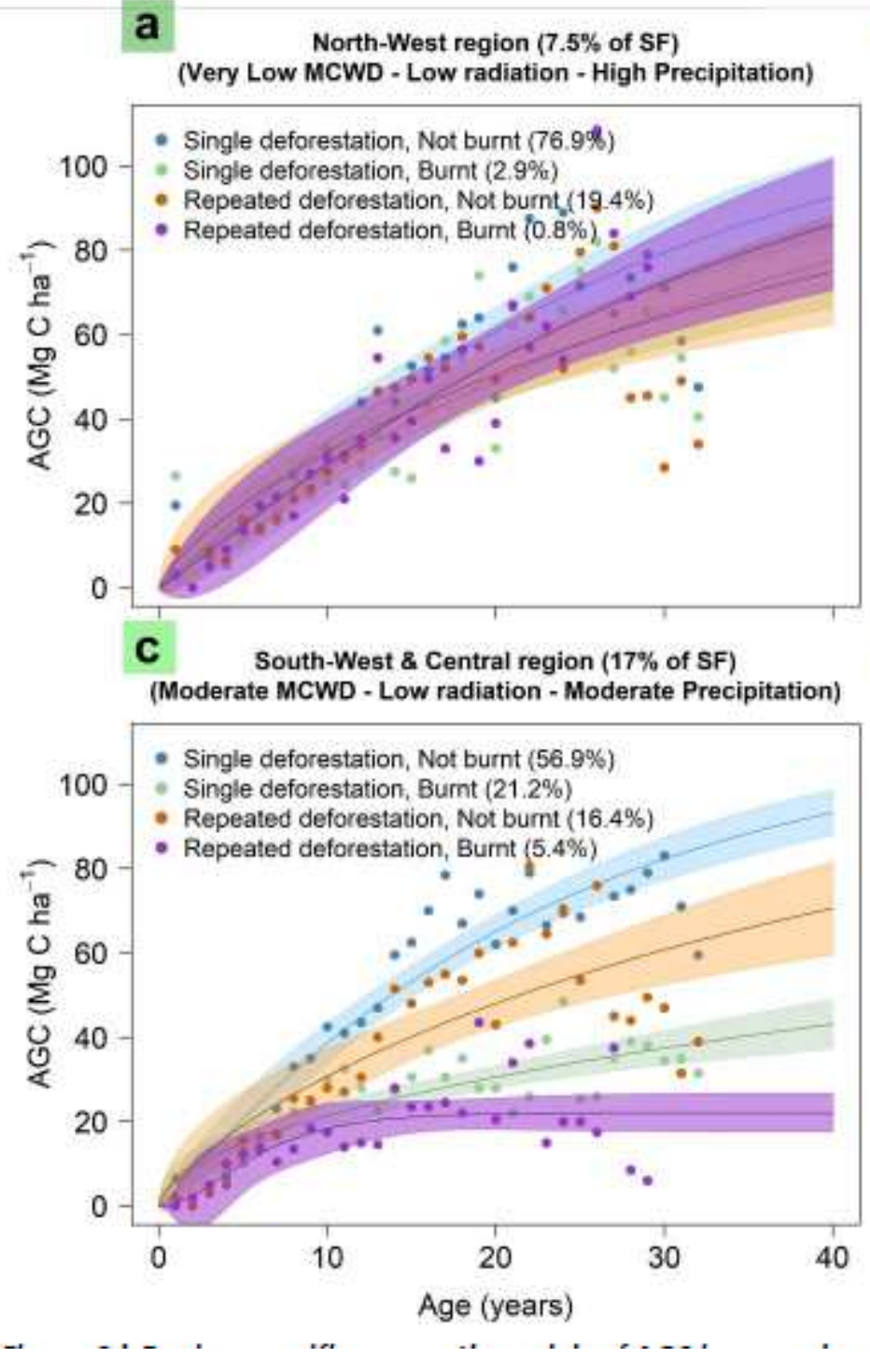

b

North-East \& Central-North (17.3\% of SF) (Low MCWD - High radiation - High Precipitation)

- Single deforestation, Not burnt (55.3\%)

- Single deforestation, Burnt (15.6\%)

- Repeated deforestation, Not burnt (21.6\%)

- Repeated deforestation, Burnt (7.5\%)

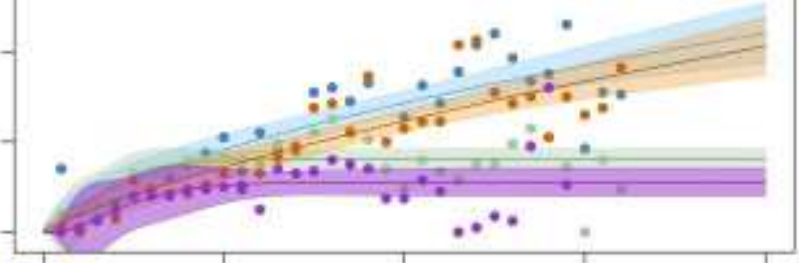

d South-East \& North region ( $58.2 \%$ of SF) (Very high MCWD - Moderate radiation - Low Precipitation)

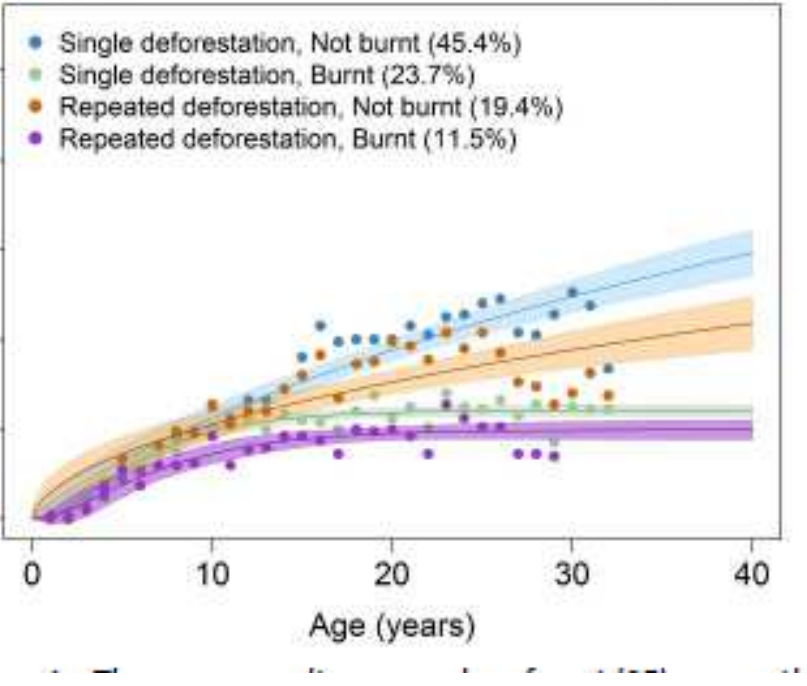

\section{Figure 3}

Region-specific regrowth models of AGC in secondary forests. The corresponding secondary forest (SF) regrowth models for the regions identified in Figure 2a. In each region, the climatological variables (Maximum Cumulative Water Deficit (MCWD), Shortwave radiation and annual precipitation are similar and the regrowth due to different kinds of disturbance is shown. (a) North-West region, (b) North-East and Central-North region, (c) South-West and Central region, (d) South-East and North region. The legends show the number of secondary forests that are affected by the type of disturbance in each region. Shading denotes the $95 \%$ confidence interval of the models based on the median value of the initial data for each age - dots in figures. See Supplementary Table 9 for quantitative interpretations of the qualitative definitions given here, for example "Low precipitation". 


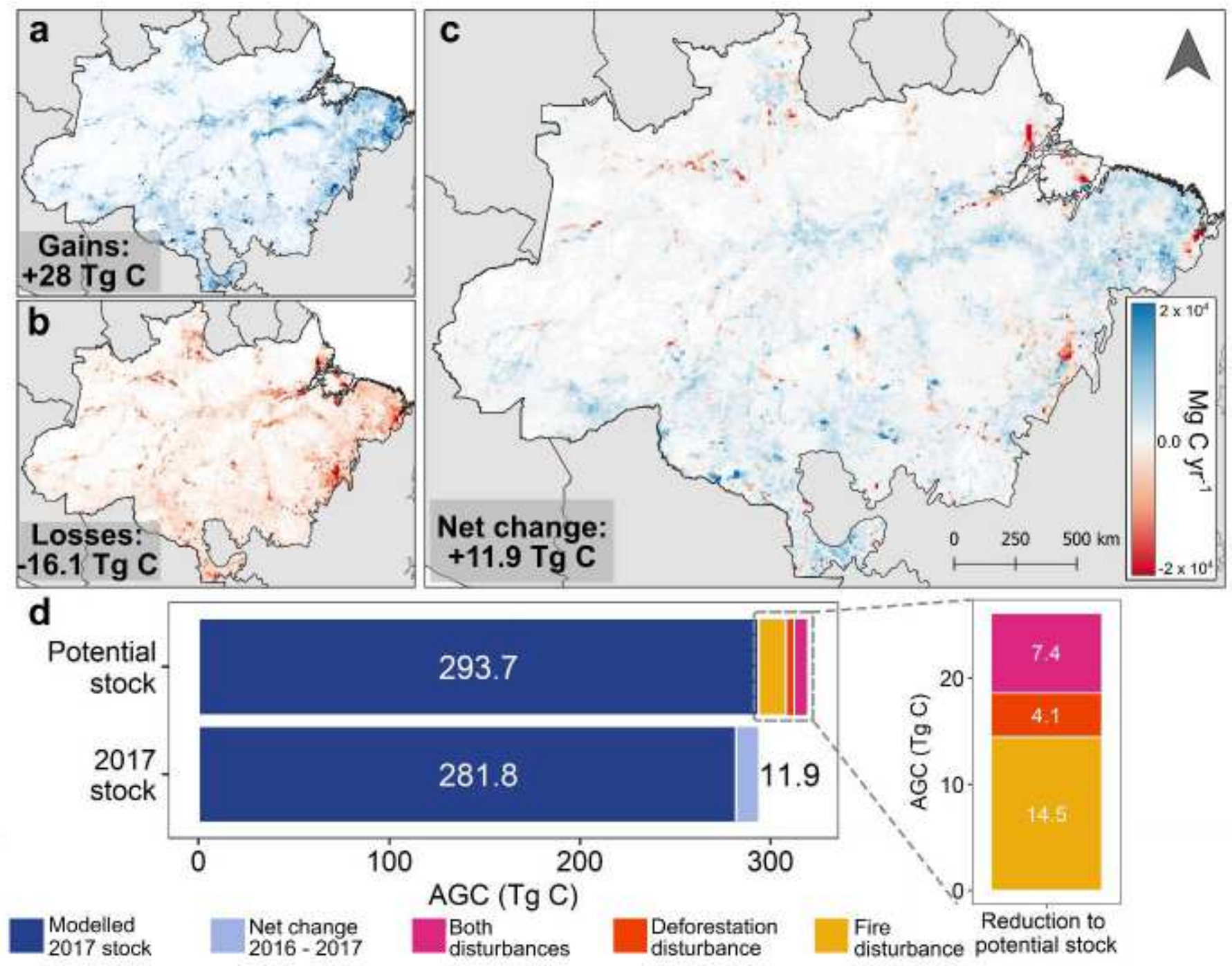

Figure 4

The modelled and potential secondary forest 2017 carbon stock. This includes the AGC gains from forests growth (a) and losses from forest loss (b) to provide a net change in the carbon stock between 2016 and 2017 per $0.1^{\circ}$ grid (c) as well as the potential total carbon stock in 2017 if none of the forest experienced any kind of disturbance (d). 

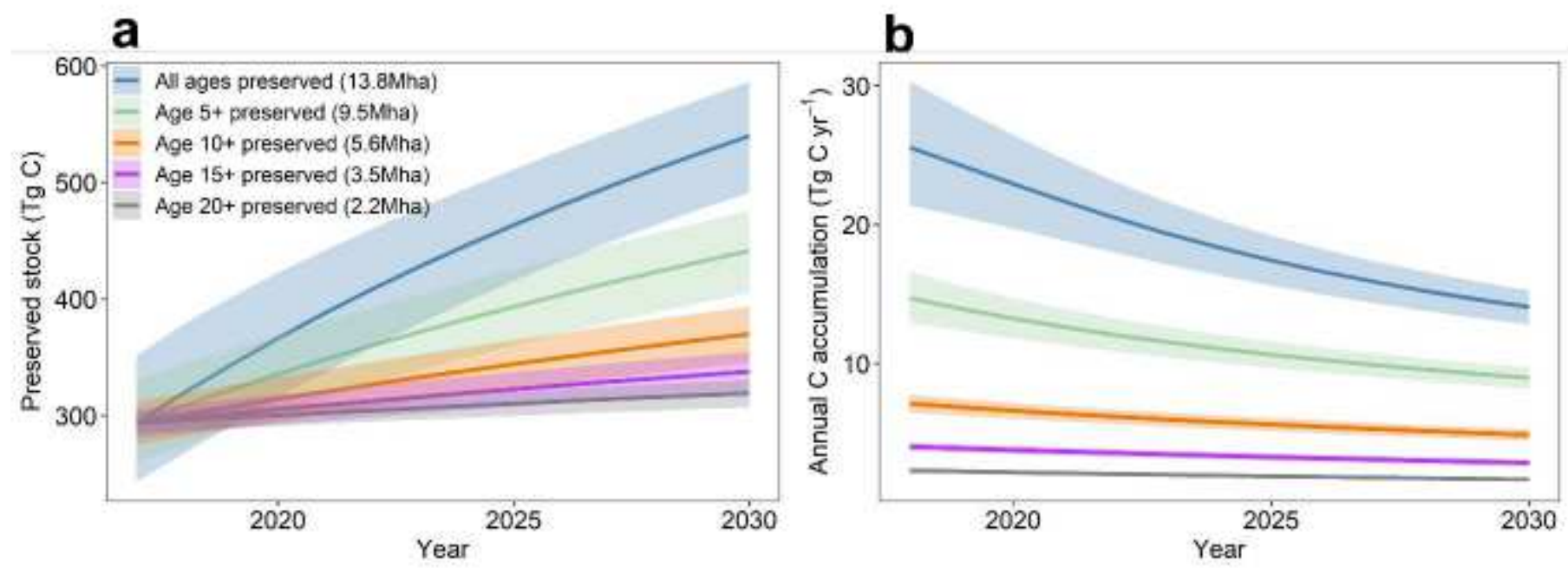

Figure 5

The future carbon stock and carbon accumulation in Amazonian secondary forests. The changes to the carbon stock (a) and annual carbon accumulation (b) are calculated for the coming decade, considering different scenarios of preservation. Shading denotes the $95 \%$ confidence interval of the regrowth model.

\section{Supplementary Files}

This is a list of supplementary files associated with this preprint. Click to download.

- supplementaryHeinrichetalsubmissionNatCommssep2020.pdf 